\title{
Optimized Heating Rate and Soot-catalyst Ratio for Soot Oxidation over $\mathrm{MoO}_{3}$ Catalyst
}

\author{
Congwei Mei ${ }^{1}$, Deqing $\mathrm{Mei}^{1 *}$, Shan Yue ${ }^{1}$, Zong Chen ${ }^{1}$, Yinnan Yuan ${ }^{2}$ \\ ${ }^{1}$ School of Automobile and Traffic Engineering, Jiangsu University, Zhenjiang, \\ Jiangsu 212013, China \\ ${ }^{2}$ School of Energy, Soochow University, Suzhou, Jiangsu 215006, China
}

Received: $4^{\text {th }}$ December 2016; Revised: $13^{\text {rd }}$ June 2017; Accepted: $9^{\text {th }}$ April 2017; Available online: 27th October 2017; Published regularly: December 2017

\begin{abstract}
$\mathrm{MoO}_{3}$ is now utilized as a promising catalyst due to its high activity and favorable mobility at low temperature. Its spectral data and surface microstructures were characterized by Fourier transform infrared spectra (FT-IR) and Field emission scanning electron microscope (FESEM). Thermo-analysis of the carbon black was performed over nano- $\mathrm{MoO}_{3}$ catalyst in a thermogravimetric analyzer (TGA) at various heating rates and soot-catalyst ratios. Through the analysis of kinetic parameters, we found that the heat transfer effect and diffusion effect can be removed by setting lower heating rates and soot-catalyst ratios. Therefore, a strategy for selecting proper thermogravimetric parameters were established, which can contribute to the better understanding of thermo-analytical process. Copyright (C) 2017 BCREC Group. All rights reserved
\end{abstract}

Keywords: diesel soot; kinetic parameters; nano- $\mathrm{MoO}_{3}$; thermogravimetric parameters

How to Cite: Mei, C., Mei, D., Yue, S, Chen, Z., Yuan, Y. (2017). Optimized Heating Rate and Sootcatalyst Ratio for Soot Oxidation over $\mathrm{MoO}_{3}$ Catalyst. Bulletin of Chemical Reaction Engineering \& Catalysis, 12 (3): 408-414 (doi:10.9767/bcrec.12.3.845.408-414)

Permalink/DOI: https://doi.org/10.9767/bcrec.12.3.845.408-414

\section{Introduction}

Soot particulates in the exhaust from diesel engines have brought great harm to human health, which touches off a rapid technology development in emission reduction. Filters can capture soot particulates from the exhaust, but the filters must be regenerated periodically [1$3]$. This process can be continuous if a highperformance catalyst coated on the filter can make the device regenerate under practical conditions. It is very important to find some innovative catalysts which can reduce the combustion temperature of particulates.

* Corresponding Author.

E-mail: meideqing@ujs.edu.cn (D. Mei)

Telp.: +86-13862445897
Several catalytic systems based on transition metal oxides, single or mixed, have been explored for soot oxidation [4]. Among them, $\mathrm{MoO}_{3}$ seems to be the most promising one. Recent researches have shown that $\mathrm{MoO}_{3}$ presents an extremely active performance for soot combustion reaction allowing for lower combustion temperatures around $500^{\circ} \mathrm{C}$ and higher selectivity to $\mathrm{CO}_{2}[3,5]$. This remarkable performance may be due to the favorable mobility of molybdenum oxide, either by the surface migration or melting and gas phase transportation with a high partial pressure of $\mathrm{MoO}_{3}$ [3].

Proper thermogravimetric parameters such as model gas composition, flow rate, crucible type, heating rate and soot-catalyst ratio are very important for catalytic oxidation experiments. Otherwise, inappropriate setup could 
make the kinetics-controlled regions deviate into diffusion-controlled regions [6,7]. Especially, the heating rate exerts important effects on results of soot oxidation mainly due to the great influence of temperature on the oxidation reactivity [8].

Nevertheless, the catalyst performance was heavily affected by soot-catalyst ratios. There is no clear specification about soot-catalyst ratios, although many researchers have mixed small quantity of soot with large quantity of catalysts to assure quick combustion of soot. It is still difficult to define an optimal soot-catalyst ratio to avoid diffusion effects.

In this work, soot oxidation kinetics under the catalytic role of $\mathrm{MoO}_{3}$ was comprehensively analyzed at various heating rates as well as soot-catalyst ratios, based on Coats-Redfern method. With the assistance of kinetic parameters analysis, a strategy for the determination of optimized thermo gravimetric parameters was developed.

\section{Materials and Method}

\subsection{Sample preparation}

A commercial carbon black supplied by Degussa Company was used as a model of diesel soot. It owns a specific surface area of $100 \mathrm{~m}^{2} / \mathrm{g}$, with an average size of $25 \mathrm{~nm}$ and the density of $130 \mathrm{~g} / \mathrm{L}$. The carbon black has been traditionally applied to replace diesel soot in TG experiments due to its fine repeatability [6]. The catalyst adopted in this study is a commercial nano-scale molybdenum trioxide $\mathrm{MoO}_{3}$ from Beijing DK Company (purity 99.9\%). In general, the catalyst and soot were mixed in a tight contact state either or a loose contact state. The tight contact can be obtained by milling catalyst with soot together. However, the actual contact between the soot with catalyst in filters seems loose. So, the loose contact state was usually prepared for catalytic oxidation experiments. In this study, samples were prepared by mixing catalysts and the carbon black with ratios of 95:5, 90:10, and 85:15, respectively. The particulate concentrations are referred to as 5 $\mathrm{wt} \%, 10 \mathrm{wt} \%$, and $15 \mathrm{wt} \%$. The loose contact was achieved by manually mixing catalysts with the carbon black in a mortar with a spatula for 3 minutes till a homogeneous state [8, 9].

\subsection{Catalyst Characterization}

Thermogravimetric experiments were conducted in a TGA/DSC1 analyzer, while the Fourier transform infrared (FT-IR) spectra were recorded with a Nicolet Nexus 470 spectrometer. It can detect and recognize a variety of spectral data. The main technical parameters of the TGA/DSC1 analyzer are shown in Table 1. The initial quantity of sample was about 6 $\mathrm{mg}$ and the heating rates were set at 10,15 and $20{ }^{\circ} \mathrm{C} / \mathrm{min}$, respectively. In accordance with the practical oxygen conditions in diesel exhaust, a simulation atmosphere of $13 \% \mathrm{O}_{2} / \mathrm{N}_{2}$ in furnace was specified with a gas flow rate of $60 \mathrm{~mL} / \mathrm{min}$. All runs were shown in Table 2.

\subsection{Mathematical modeling}

Kinetic studies were performed in a thermogravimetric analyzer based on Coats-Redfern method [10]. Usually, the change in extent of reaction $(a)$ is used to research the solid state reactions kinetics:

$$
\alpha=\frac{m_{0}-m}{m_{0}-m_{\infty}} \times 100 \%
$$

In this equation, $m_{o}, m$, dan $m_{\infty}$ are initial sample mass, sample mass at time $t$ and sample mass at the end of experiment, respectively. Using extent of reaction, the rate of a solid state reaction can be usually described by:

$$
\mathrm{d} \alpha / \mathrm{d} t=k f(\alpha)
$$

The temperature dependence of the reaction rate is usually described by the Arrhenius equation:

$$
k=A \exp (-E / R T)
$$

In this equation, $A$ is the pre-exponential factor, $E$ is the activation energy, $T$ is the absolute temperature and $R$ is the molar gas constant. The equation of $f(a)=(1-a)^{\mathrm{n}}$ is the reaction model. Under non-isothermal conditions, in which a sample is heated at a constant rate, the explicit temporal in Equation (2) is eliminated through the trivial transformation:

$$
\frac{d \alpha}{d T}=\frac{A}{\beta} \exp \left(\frac{-E}{R T}\right) f(\alpha)
$$

In this equation, $\beta$ is the constant heating rate. Finally, Coats-Redfern equations were obtained through integral transformation:

When $\mathrm{n} \neq 1$ :

$$
\ln \left[\frac{1-\ln (1-\alpha)^{1-n}}{T^{2}(1-n)}\right]=\ln \left[\frac{A R}{\beta E}\left(1-\frac{2 R T}{E}\right)\right]-\frac{E}{R T}
$$


When $\mathrm{n}=1$ :

$$
\ln \left[\frac{-\ln (1-\alpha)}{T^{2}}\right]=\ln \left[\frac{A R}{\beta E}\left(1-\frac{2 R T}{E}\right)\right]-\frac{E}{R T}
$$

Plotting the left hand side of Equation (6), which include $-\ln (1-a)$ versus $1 / T$, gives $E$ and $A$ from the slope and intercept, respectively.

\section{Results and Discussion}

\subsection{Catalyst Characterizations}

Fourier transform infrared (FT-IR) spectra were recorded with a Nicolet Nexus 470 spectrometer. It can detect and recognize a variety of spectral data. The FT-IR spectrogram of $\mathrm{MoO}_{3}$ was shown in Figure 1. The corresponding $\mathrm{O}-\mathrm{H}$ stretching modes are responsible for the broad bands at $3429 \mathrm{~cm}^{-1}$ and $1628 \mathrm{~cm}^{-1}$, which indicate small amounts of water molecules absorbed by the surface of $\mathrm{MoO}_{3}$. The sharp strong peaks at $988 \mathrm{~cm}^{-1}$ and $1383 \mathrm{~cm}^{-1}$ are supposed to be the stretching modes of $(\mathrm{Mo}=\mathrm{O})$ groups. Two evident and broad bands formed at $875 \mathrm{~cm}^{-1}$ and $624 \mathrm{~cm}^{-1}$ can be confidently assigned to Mo-O-Mo groups. The results of fourier infrared analysis are basically identical with literature [11].

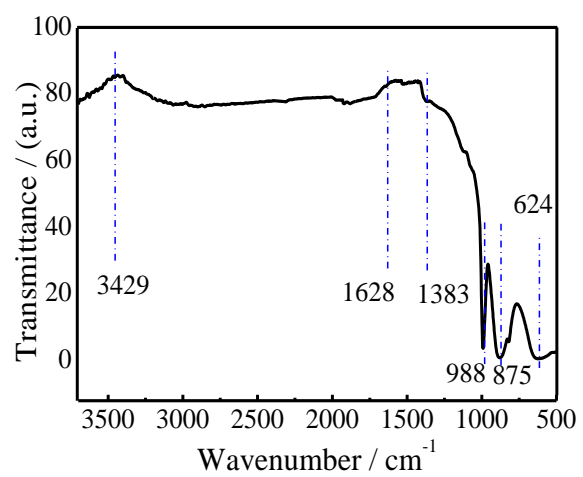

Figure 1. FT-IR spectra of the catalyst $\mathrm{MoO}_{3}$

Table 1. Main specifications of TGA/DSC1 thermogravimetric analyzer

\begin{tabular}{ll}
\hline Model & TGA $/ \mathrm{DSC} 1 \mathrm{SF}$ \\
ambient temperature $/\left({ }^{\circ} \mathrm{C}\right)$ & $15 \sim 35$ \\
resolution $/(\mu \mathrm{g})$ & 0.1 \\
maximum weight $/(\mathrm{g})$ & 1.0 \\
isothermal stability $/\left({ }^{\circ} \mathrm{C}\right)$ & 0.1 \\
isothermal temperature accu- & 0.15 \\
racy $/\left({ }^{\circ} \mathrm{C}\right)$ & \\
crucible dimension & $\Phi 5 \mathrm{~mm} \times 4.5 \mathrm{~mm}$ \\
crucible volume $/(\mu \mathrm{l})$ & $\approx 70$ \\
heating rate $/\left({ }^{\circ} \mathrm{C} / \mathrm{min}\right)$ & $0.1 \sim 250$ \\
temperature control range $/\left({ }^{\circ} \mathrm{C}\right)$ & ambient tempera- \\
& ture $\sim 1100$ \\
\hline
\end{tabular}

The structure and morphology of $\mathrm{MoO}_{3}$ were reflected by images from an S-4800 field emission scanning electron microscope (FESEM) operating at $15 \mathrm{kV}$. Before FESEM detecting, the sample was dusted on an adhesive conductive carbon paper attached on a brass mount and coated with platinum.

The FESEM image of $\mathrm{MoO}_{3}$ is presented in Figure 2. A large number of microspheres with diameters of 100-200 $\mathrm{nm}$ and nano-flakes with lattice fringes can be evidently observed. The nanosphers of $\mathrm{MoO}_{3}$ were prepared by the liquid phase deposition method. The $\mathrm{MoO}_{3}$ of spherical structure owns many particular physical attributes, such as great specific surface area, excellent thermal conductivity and mechanical flexibility which all bring about favorable catalytic performances $[12,13]$.

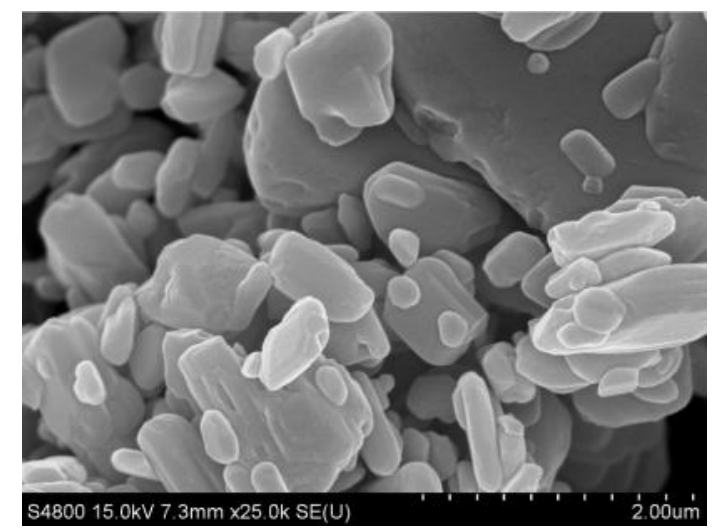

Figure 2. FESEM image of the catalyst $\mathrm{MoO}_{3}$

Table 2. Experimental variables for TGA experiments

\begin{tabular}{ccc}
\hline $\begin{array}{c}\text { Scheme } \\
\text { number }\end{array}$ & $\begin{array}{c}\text { Heating rate } \\
\left({ }^{\circ} \mathrm{C} / \mathrm{min}\right)\end{array}$ & $\begin{array}{c}\text { Particulate } \\
\text { concentration }(\mathrm{wt} \%)\end{array}$ \\
\hline $\mathrm{A}$ & 10 & 5 \\
$\mathrm{~B}$ & 10 & 10 \\
$\mathrm{C}$ & 10 & 15 \\
$\mathrm{D}$ & 15 & 5 \\
$\mathrm{E}^{*}$ & 15 & 10 \\
$\mathrm{~F}$ & 15 & 15 \\
$\mathrm{G}$ & 20 & 5 \\
$\mathrm{H}$ & 20 & 10 \\
$\mathrm{I}$ & 20 & 15 \\
$\mathrm{~J}$ & 10 & 100 \\
$\mathrm{~K}$ & 15 & 100 \\
$\mathrm{~L}$ & 20 & 100 \\
\hline
\end{tabular}

$E^{*}$ : The central point, where the triplicates were performed 


\subsection{Catalytic Activity}

A repeatability test was run at the scheme $\mathrm{E}^{*}$ in Table 2, with a heating rate of $15{ }^{\circ} \mathrm{C} / \mathrm{min}$ and the carbon black concentration of $10 \mathrm{wt} \%$. The thermogravimetric results for scheme $\mathrm{E}^{*}$ are shown in Figure 3. There was a very small fraction of weight loss before $250{ }^{\circ} \mathrm{C}$, normally due to the evaporation of moisture. In view of this, only the data above $400{ }^{\circ} \mathrm{C}$ are presented. The carbon black was mainly oxidized at the temperature interval from $450{ }^{\circ} \mathrm{C}$ to $600{ }^{\circ} \mathrm{C}$. Still, there is a bit of weight loss above $700^{\circ} \mathrm{C}$, perhaps because of the sublimation of molybdenum [3]. A good repeatability in the three curves indicates that the initial quantity of sample, heating rate, gas flow, and furnace atmosphere are all in an appropriate range.

Kinetic parameters resulted from TG and DTG data are shown in Table 3. The values of activation energy for samples with various catalyst fractions lied between $116.3 \mathrm{~kJ} / \mathrm{mol}$ and $155.3 \mathrm{~kJ} / \mathrm{mol}$, and that for the carbon black was $171.8 \mathrm{~kJ} / \mathrm{mol}$ at $15^{\circ} \mathrm{C} / \mathrm{min}$. Pre-exponential factors in a logarithm form were located within 8.6 and 16.0. Both kinetic parameters of the activation energy and the pre-exponential factor were well conformed with those values found in literatures [6,14].

TG and DTG data for the $100 \mathrm{wt} \%$ carbon black at various heating rates of $10^{\circ} \mathrm{C} / \mathrm{min}, 15$ ${ }^{\circ} \mathrm{C} / \mathrm{min}$ and $20^{\circ} \mathrm{C} / \mathrm{min}$ are illustrated in Figure
4. The carbon black began to lose weight quickly above $500{ }^{\circ} \mathrm{C}$. With the increase in heating rate, a hysteresis phenomenon appeared, perhaps because the oxidation rate of the carbon black at low temperature was greatly influenced by the heat and mass transfer effects including the heat transfer of the carbon black from outside to inside and the intermediate overflowing of volatile products from internal to surfaces [6]. A high heating rate may result in a great temperature gradient from internal to surface for the carbon black, as well as from the carbon black surface to the furnace chamber, which lowers the weight loss rate of the carbon black. As a re-

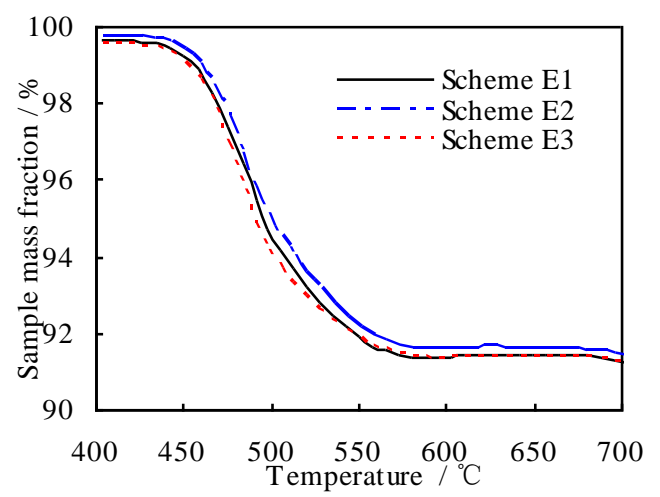

Figure 3. Sample mass vs. temperature for the Scheme E

Table 3. Kinetic parameters for each experimental scheme

\begin{tabular}{cccccc}
\hline $\begin{array}{c}\text { Scheme } \\
\text { number }\end{array}$ & Fitted line & $\begin{array}{c}\text { Pre-exponential } \\
\text { factor }(A) \\
(\mathrm{L} / \mathrm{min})\end{array}$ & $\begin{array}{c}\text { Activation } \\
\text { Energy }(E) \\
(\mathrm{kJ} / \mathrm{mol})\end{array}$ & $\mathrm{R}^{2}$ & $\ln (A)$ \\
\hline $\mathrm{A}$ & $\mathrm{y}=-14.7004 \mathrm{x}+3.8047$ & $6.60 \times 10^{3}$ & 122.2 & 0.996 & 8.80 \\
$\mathrm{~B}$ & $\mathrm{y}=-15.0078 \mathrm{x}+4.2714$ & $1.07 \times 10^{4}$ & 124.7 & 0.992 & 9.28 \\
$\mathrm{C}$ & $\mathrm{y}=-18.6932 \mathrm{x}+8.9952$ & $1.51 \times 10^{6}$ & 155.3 & 0.991 & 14.23 \\
$\mathrm{D}$ & $\mathrm{y}=-14.4260 \mathrm{x}+4.4708$ & $1.89 \times 10^{4}$ & 119.9 & 0.988 & 9.85 \\
$\mathrm{E}^{1}$ & $\mathrm{y}=-14.6120 \mathrm{x}+4.7858$ & $2.63 \times 10^{4}$ & 121.4 & 0.987 & 10.18 \\
$\mathrm{E}^{2}$ & $\mathrm{y}=-14.6422 \mathrm{x}+4.1053$ & $1.33 \times 10^{4}$ & 121.7 & 0.981 & 9.50 \\
$\mathrm{E}^{3}$ & $\mathrm{y}=-13.9988 \mathrm{x}+3.3126$ & $5.77 \times 10^{3}$ & 116.3 & 0.987 & 8.66 \\
$\mathrm{~F}$ & $\mathrm{y}=-18.0931 \mathrm{x}+9.1178$ & $2.47 \times 10^{6}$ & 150.4 & 0.983 & 14.72 \\
$\mathrm{G}$ & $\mathrm{y}=-14.9026 \mathrm{x}+6.2105$ & $1.48 \times 10^{5}$ & 123.8 & 0.984 & 11.91 \\
$\mathrm{H}$ & $\mathrm{y}=-14.5576 \mathrm{x}+5.3025$ & $5.85 \times 10^{4}$ & 121.0 & 0.982 & 10.98 \\
$\mathrm{I}$ & $\mathrm{y}=-18.0999 \mathrm{x}+10.1083$ & $8.88 \times 10^{6}$ & 150.4 & 0.991 & 16.00 \\
$\mathrm{~K}$ & $\mathrm{y}=-20.6782 \mathrm{x}+9.9461$ & $6.47 \times 10^{3}$ & 171.8 & 0.992 & 15.7 \\
\hline
\end{tabular}

* $y$ is the $\ln \left((-\ln (1-a)) / T^{2}\right)$, and $x$ is the $1 / T$ 
sult, TG, and DTG profiles shift to the high temperature area.

Figures 5 and 6 respectively present the tendency of the logarithmic of pre-exponential factor and activation energy with the heating rate. In general, the pre-exponential factor indicates the collision frequency of activated molecules. The greater pre-exponential factor means more effective collisions between molecules. As shown in Figure 5, the pre-exponential factor slightly increases with the growth of heating rate from $10{ }^{\circ} \mathrm{C} / \mathrm{min}$ to $15{ }^{\circ} \mathrm{C} / \mathrm{min}$ at the same particulate concentration, but it dramatically increases at the heating rate of $20{ }^{\circ} \mathrm{C} / \mathrm{min}$. It may be easily supposed that with the increase in the heating rate, more carbon blacks participate in reacting per unit time and the molecules' collisions are growing. Besides, more carbon blacks were accumulated to be oxidized at high temperature due to the previous lower level of decomposition. Therefore, no apparent inflection point on DTG was perceived owing to insufficient oxidation at a rapid heating rate $[14,15]$.

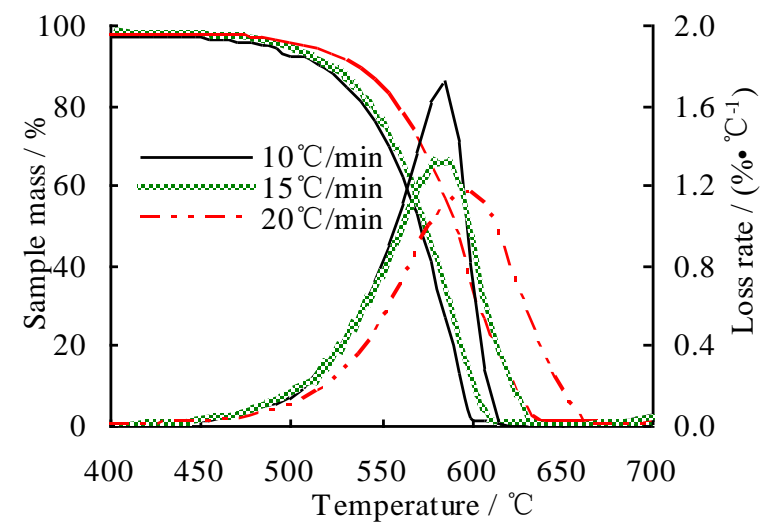

Figure 4. TG-DTG data for the carbon black at different heating rates

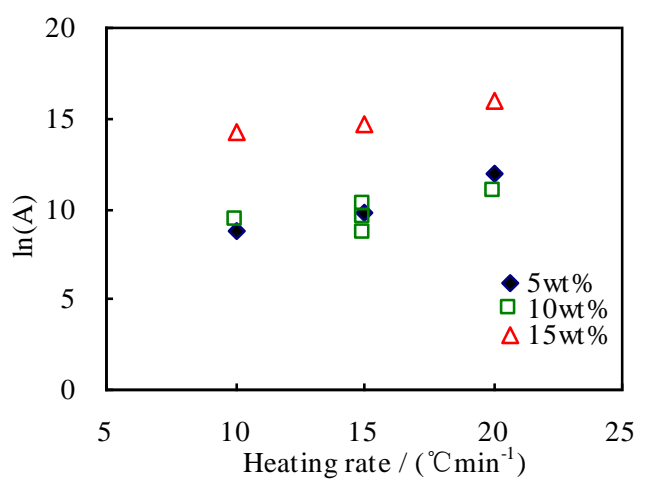

Figure 5. Logarithm of pre-exponential factor $\ln (A)$ as a function of the heating rate
In Figure 6, the activation energy has little variance with the heating rate at the same particulate concentration. Through a comprehensive consideration for pre-exponential factor and activation energy, the influence of heating rate within $10-15{ }^{\circ} \mathrm{C} / \mathrm{min}$ on kinetic parameters is extremely weak. It suggests that the reaction conditions hardly reach the heat-transfer limitations. Therefore, the low heating rate is proper for catalytic oxidation in thermogravimetric analyzer [16].

TG and DTG features of different particulate concentrations at the heating rate of 15 ${ }^{\circ} \mathrm{C} / \mathrm{min}$ are shown in Figure 7. TG and DTG profiles of the carbon black containing catalysts shift to the low temperature region by a larger step. Further, for samples of the carbon black with $\mathrm{MoO}_{3}$ catalysts, the thermogravimetric features transfer slightly to the low temperature with an obvious increase in catalyst content. Oxidation parameters of the carbon black catalyzed by $\mathrm{MoO}_{3}$ at different particulate concentrations are presented in Table 4. As compared with the neat carbon black, the

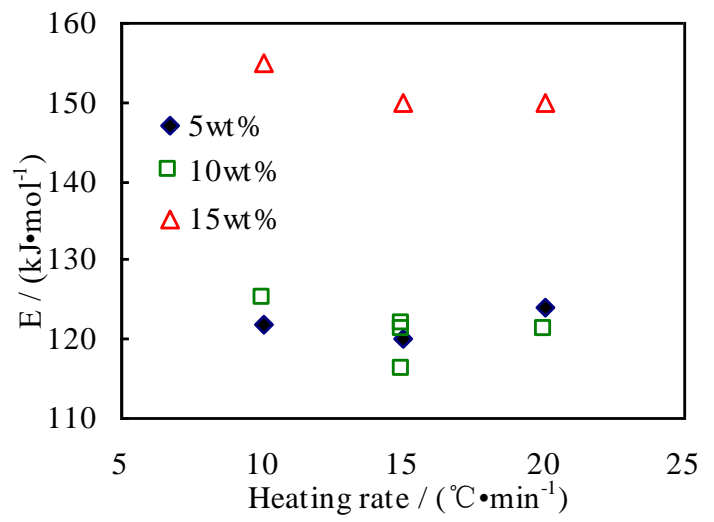

Figure 6. Activation energy $\mathrm{E}$ as a function of the heating rate

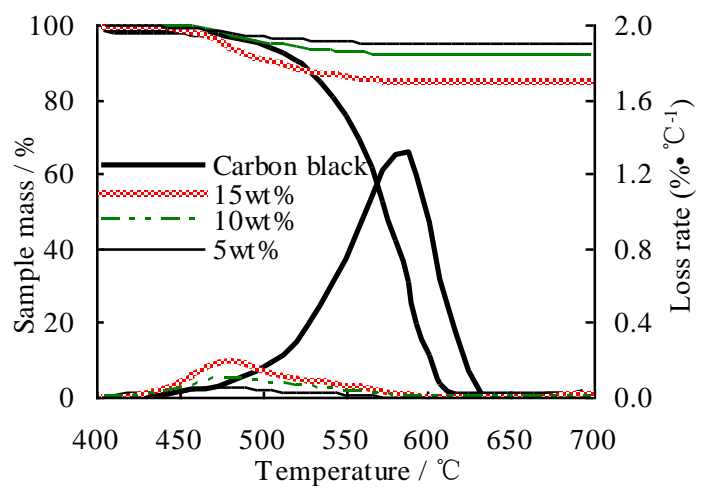

Figure 7. TG-DTG data for the carbon black at various particulate concentrations 
initial ignition temperature $T_{i}$ of the $5 \mathrm{wt} \%$ carbon black, the temperature of weight loss peak $T_{p}$ and the complete burnout temperature $T_{f}$ are drastically reduced by $72.1{ }^{\circ} \mathrm{C}, 114.5^{\circ} \mathrm{C}$, and $76.6{ }^{\circ} \mathrm{C}$, respectively. The best catalytic performance of $\mathrm{MoO}_{3}$ occurred at the particulate concentration of $5 \mathrm{wt} \%$.

Considering the influence of the particulate concentration on kinetic parameters, Figure 8 and Figure 9 respectively show the trend of pre-exponential factor and activation energy changing with the particulate concentration. Both the pre-exponential factors in the logarithm form and activation energy keep in the same low level at the particulate concentrations of $5 \mathrm{wt} \%$ and $10 \mathrm{wt} \%$, while that at the particulate concentration of $15 \mathrm{wt} \%$ are particularly high, which indicates an apparent increase in the transfer resistance, maybe owing to poor effects of mass transfer at high particulate concentrations. In view of this, the combustion process will be greatly affected by the oxygen diffusion and perhaps some particulates can not contact sufficiently with oxygen. In addition, a very low contact rate between the catalyst and the carbon black resulted from higher particulate concentration may make the heat transfer difficult at rapid heating. Mean-

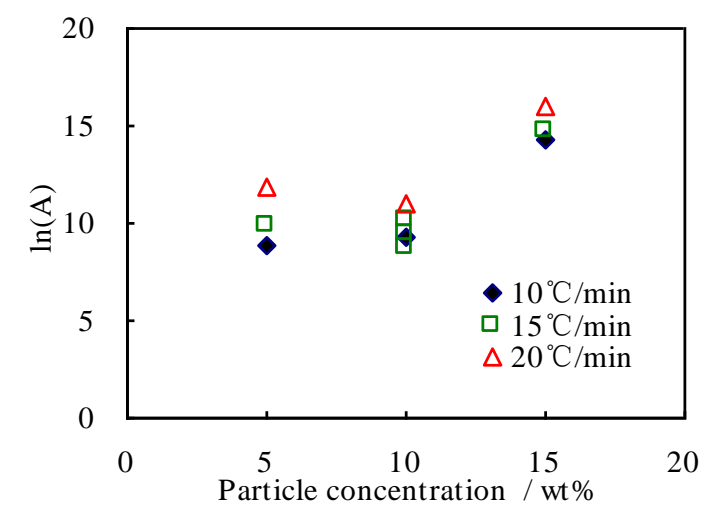

Figure 8. Logarithm of pre-exponential factor $\ln (A)$ as a function of particulate concentration

Table 4. Catalytic oxidation parameters at various particulate concentrations

\begin{tabular}{ccccc}
\hline Sample & $\begin{array}{c}T_{i} \\
\left({ }^{\circ} \mathrm{C}\right)\end{array}$ & $\begin{array}{c}T_{p} \\
\left({ }^{\circ} \mathrm{C}\right)\end{array}$ & $\begin{array}{c}T_{f} \\
\left({ }^{\circ} \mathrm{C}\right)\end{array}$ & $\begin{array}{c}\text { Maximum } \\
\text { weight loss } \\
\text { rate }\left(\% /{ }^{\circ} \mathrm{C}\right)\end{array}$ \\
\hline $5 \mathrm{wt} \%$ & 440.4 & 473.5 & 548.2 & 0.06 \\
$10 \mathrm{wt} \%$ & 450.8 & 481.8 & 551.5 & 0.10 \\
$15 \mathrm{wt} \%$ & 458.5 & 484.1 & 559.3 & 0.19 \\
$\begin{array}{c}\text { Carbon } \\
\text { black }\end{array}$ & 512.5 & 588.0 & 624.8 & 1.31 \\
\hline
\end{tabular}

while, pyrolytic products can not spread out in time and non-catalytic oxidation is relatively increased, which consequentially indicates a higher activation energy. Therefore, suiting current oxidation conditions in this study, the appropriate particulate concentration should no more than $10 \mathrm{wt} \%$ to reduce the deviation of experiment $[6,17,18]$.

In order to minimize the errors of the kinetic parameters, it is necessary to reduce the resistance of mass transfer as well as diffusion effects. As a result of current study, catalytic oxidation experiments should be performed at lower particulate concentrations between 5 $\mathrm{wt} \%$ and $10 \mathrm{wt} \%$ and lower heating rates between $10^{\circ} \mathrm{C} / \mathrm{min}$ and $15{ }^{\circ} \mathrm{C} / \mathrm{min}$ ).

\section{Conclusions}

Soot oxidation under catalysts is greatly affected by the specified thermogravimetric parameters. The estimated kinetic parameters revealed little influence of the heating rate on the activation energy. But the pre-exponential factor was increased slightly with the growth in the heating rate, especially a large rise at the heating rate of $20^{\circ} \mathrm{C} / \mathrm{min}$. Both activation energy and the pre-exponential factor presented a high level resulted from diffusion effects at a high soot-catalyst ratio of $15 \mathrm{wt} \%$. Therefore, for catalytic oxidation studies, TG experiments should be performed at a heating rate lower than $15{ }^{\circ} \mathrm{C} / \mathrm{min}$ and the particulate concentrations no more than $10 \mathrm{wt} \%$ in order to obtain the accurate and reliable values of the pre-exponential factor and the activation energy.

Thereby, based on the reasonability evaluations on the pre-exponential factor and activation energy of each experiment scheme, a strat-

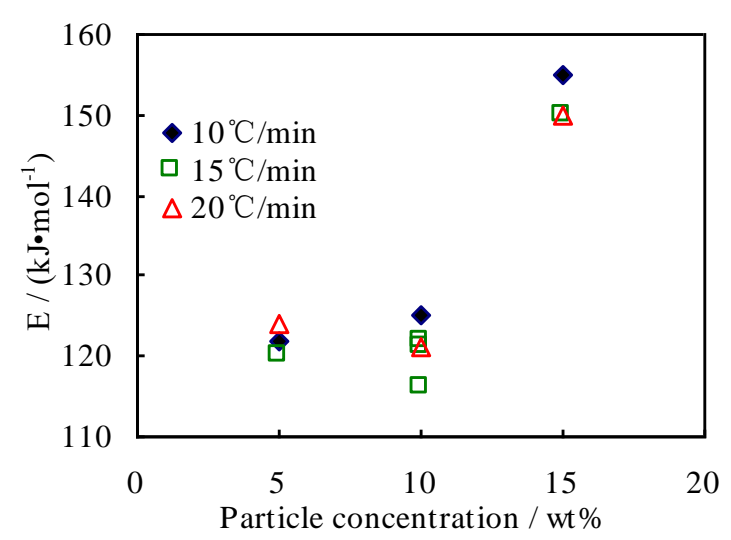

Figure 9. Activation energy $E$ as a function of particulate concentration 
egy for determining the optimized thermogravimetric parameters was built up. This strategy can assist to reduce or avoid the heat transfer resistance and diffusion effect due to inappropriate experimental conditions. Overall, the significance of the results and comprehensive understanding was improved with this strategy for soot oxidation.

\section{Acknowledgement}

The authors wish to express their appreciation for the funds from the National Natural Science Foundations of China (No. 51376095 and No. 51506101) and the Priority Academic Program Development of Jiangsu Higher Education Institutions (PAPD), which supported this study.

\section{References}

[1] Aneggi, E., Divins, N.J., Leitenburg, C., Llorca, J., Trovarelli, A. (2014). The formation of nanodomains of $\mathrm{Ce}_{6} \mathrm{O}_{11}$ in ceria catalyzed soot combustion. Journal of Catalysis. 312: 191-194.

[2] Nhon, Y.N.H., Magan, H.M., Petit, C. (2004). Catalytic diesel particulate filter evaluation of parameters for laboratory studies. Applied Catalysis B: Environmental. 49: 127-133.

[3] Braun, S., Appel, L.G., Schmal, M. (2005). Molybdenum species on alumina and silica supports for soot combustion. Catalysis Communications. 6: 7-12.

[4] Leocadio, I.C.L., Braun, S., Schmal, M. (2004). Diesel soot combustion on $\mathrm{Mo} / \mathrm{Al}_{2} \mathrm{O}_{3}$ and $\mathrm{V} / \mathrm{Al}_{2} \mathrm{O}_{3}$ catalysts: investigation of the active catalytic species. Journal of Catalysis. 223: 114-121.

[5] Kumar, P.A., Tanwar, M.D., Bensaid, S., Russo, N., Fino, D. (2012). Soot combustion improvement in diesel particulate filters catalyzed with ceria nanofibers. Chemical Engineering Journal. 207-208: 258-266

[6] Sharma, H.N., Pahalagedara, L., Joshi, A., Suib, S.L., Mhadeshwar, A.B. (2012). Experimental study of carbon black and diesel engine soot oxidation kinetics using thermogravimetric analysis. Energy \& Fuels. 26: 56135625.

[7] Roduit, B., Maciejewski, M., Baiker, A. (1996). Influence of experimental conditions on the kinetic parameters of gas-solid reactionsparametric sensitivity of thermal analysis. Thermochimica Acta. 282-283: 101-119
[8] Hensgen, L., Stöwe, K. (2011). Soot-catalyst contact studies in combustion process using nano-scaled ceria as test material. Catalyst Today. 159: 100-107

[9] Okekunle, P.O., Pattanotai, T., Watanabe, H. (2011). Numerical and experimental investigation of intra-particle heat transfer and decomposition during pyrolysis of wood biomass. Journal of Thermal Science and Technology. 6: 360-375.

[10] Ebrahimi-Kahrizsangi, R., Abbasi, M.H. (2008). Evaluation of reliability of CoatsRedfern method for kinetic analysis of nonisothermal TGA. Transactions of Nonferrous Metals Society of China. 18: 217-221.

[11] Rathod, S.B., Lande, M.K., Arbad, B.R., Gambhire, A.B. (2014). Preparation, characterization and catalytic activity of $\mathrm{MoO}_{3} / \mathrm{CeO}_{2}-\mathrm{ZrO}_{2}$ solid heterogeneous catalyst for the synthesis of B-enaminones. Arabian Journal of Chemistry. 7: 253-260.

[12] Yang, X.F., Ding, H.Y., Zhang, D., Yan, X.H., Lu, C.Y., Qin, J.L., Zhang, R.X., Tang, H., Song, H.J. (2011). Hydrothermal synthesis of $\mathrm{MoO}_{3}$ nanobelt-graphene composites. Crystal Research and Technology. 46: 1195-1201.

[13] Deki, S., Béléké, A.B., Kotani, Y., Mizuhata, M. (2009). Liquid phase deposition synthesis of hexagonal molybdenum trioxide thin films. Journal of Solid State Chemistry. 182: 23622367.

[14] Zouaoui, N., Issa, M., Kehrli, D., Jeguirim, M. (2012). $\mathrm{CeO}_{2}$ catalytic activity for soot oxidation under $\mathrm{NO} / \mathrm{O}_{2}$ in loose and tight contact. Catalysis Today. 189: 65-69.

[15] Skreiberg, A., Skreiberg, Ø., Sandquist, J., Sørum, L. (2011). TGA and macro-TGA characterization of biomass fuels and fuel mixtures. Fuel. 90: 2182-2197.

[16] Rodríguez-Fernández, J., Oliva, F., Vázquez, R.A. (2011). Characterization of the diesel soot oxidation process through an optimized thermogravimetric method. Energy \& Fuels. 25: 2039-2048.

[17] López-Fonseca, R., Elizundia, U., Landa, I., Gutiérrez-Ortiz, M.A., González-Velasco, J.R. (2005). Kinetic analysis of non-catalytic and Mn-catalysed combustion of diesel soot surrogates. Applied Catalysis B: Environmental. 61: 150-158.

[18] Yang, J., Tanguy, P.A., Roy, C. (1995). Heat transfer, mass transfer and kinetics study of the vacuum pyrolysis of a large used tire particle. Chemical Engineering Science. 50: 19091922. 